\title{
Class-E Rectifiers and Power Converters: The Operation of the Class-E Topology as a Power Amplifier and a Rectifier with Very High Conversion Efficiencies
}

\author{
José A. García ${ }^{1}$ and Zoya Popović ${ }^{2}$ \\ ${ }^{1}$ Department of Communications Engineering, University of Cantabria, 39005 \\ Santander, Spain \\ ${ }^{2}$ Department of Electrical, Computer and Energy Engineering, \\ University of Colorado, Boulder, CO, 80309, U.S.A.
}

\section{INTRODUCTION}

In the late 70 's, the interest in reducing the value and size of reactive components moved power supply specialists to operate dc-to-dc converters at hundreds of $\mathrm{kHz}$ or even $\mathrm{MHz}$ frequencies. Passive energy storage (mainly magnetics) dominates the size of power electronics, limiting also its cost, reliability and dynamic response. Motivated by miniaturization and improved control bandwidth, they had to face the frequencydependent turn-on and turn-off losses associated with the use of rectangular waveforms in the hard-switched topologies of that time. Similar to approaches for RF/microwave power amplifiers (PAs), the introduction of resonant circuits allowed shaping either a sinusoidal voltage or current, with parasitic reactive elements absorbed by the topology in the neighborhood of the switching frequency. The resulting resonant power converters, obtained by cascading a dc-to-ac resonant inverter with a high-frequency acto-dc rectifier, first transform the dc input power into controlled ac power, and then convert it back into the desired dc output [1].

This paper provides some historic notes on the operation of the class-E topology, introduced worldwide to the RF/microwave community by Nathan O. Sokal [2], as a power inverter and as a rectifier, with very high conversion efficiencies up to microwave frequencies. Recent research advances and implementations of class-E rectifiers and dc-to-dc converters at UHF and beyond are included. Offering competitive performance in terms of efficiency for RF power recovery, together with a wide bandwidth for low-loss power conversion, their potential for some modern applications is highlighted. 


\section{THE Class-E POWER InVERTER}

A power amplifier is called an inverter in power electronics or related areas [1]. Treated as an energy converter, attention is put into the dc-to-ac conversion efficiency instead of its gain. The input signal is usually the external excitation waveform required to properly drive its switching device. The need for such a signal may be avoided if an oscillator were employed in place of the power amplifier.

Originally conceived as a RFPA in [2], the idea of using a class-E topology for zero voltage (ZVS) and zero voltage derivative switching (ZVDS) in the inverting side of a resonant power converter is attributed to Ronald J. Gutmann [3], a visiting member of Technical Staff at Bell Laboratories in 1979, on leave from Rensselaer Polytechnic Institute. A breadboard dc-to-dc converter, working at $10 \mathrm{MHz}$, was implemented, using a bipolar-based class-E PA (E10-3) available by that time from Design Automation, Lexington, MA, and a shunt-mounted harmonically tuned rectifier with a silicon Schottky diode (Motorola 1N5822). After the class-E inverter was adjusted to optimize compatibility with the rectifier, an efficiency of $68 \%$ was measured and the load regulation capability with frequency control successfully demonstrated.

A deeper insight into class-E power inverter operation was later provided in $[4,5]$, coauthored by Richard Redl, Béla Molnár and Nat Sokal. Referred to as a class-E converter, a high efficiency about $85 \%$ was measured for a $40-\mathrm{W} \quad 1.5-\mathrm{MHz}$ implementation of the schematic in Fig. 1a. An International Rectifier IRF 150 MOSFET was employed as the power switch. The experimental converter was designed and built with much less difficulty than had been expected by the authors, suggesting the class-E topology was well-suited to this application. The $100-\mathrm{W} 14-\mathrm{MHz}$ transformer-coupled converter in Fig. 1b was demonstrated in 1986 by Redl and Sokal [6], combining a high-power PA and a push-pull rectifier, with an efficiency as high as $87 \%$. Other significant contributions by the same authors may be found in $[7,8]$.

Many subsequent examples of class-E power inverters may be found in the literature, including variants of the more traditional topology in [2]. That is the case, for instance, of the second-harmonic resonant class-E inverter by Keio University researchers in 1988 [9]. This topology is extended to a continuum of class-E topologies [10], many of which do not require a RF choke coil. 


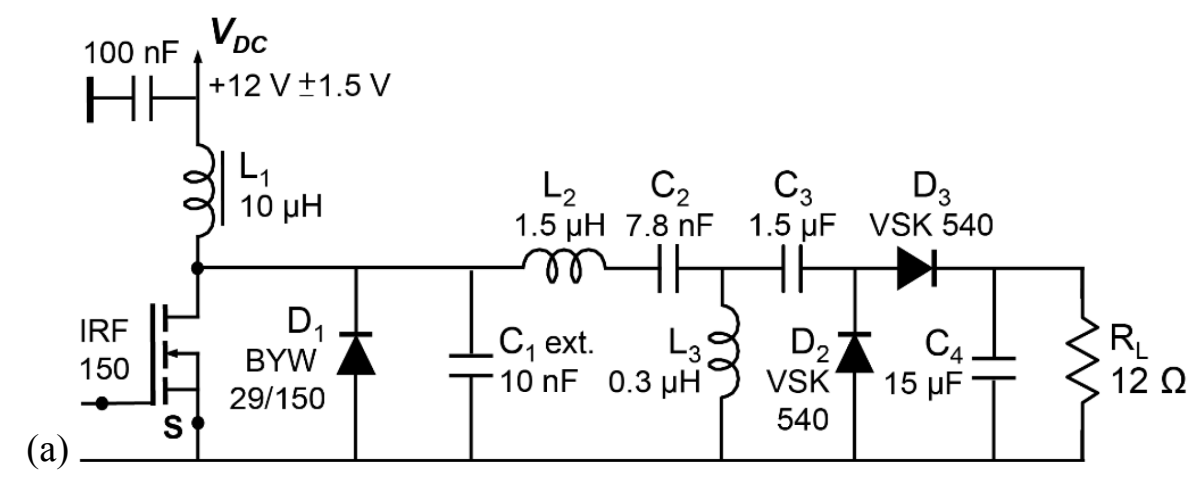

(b)

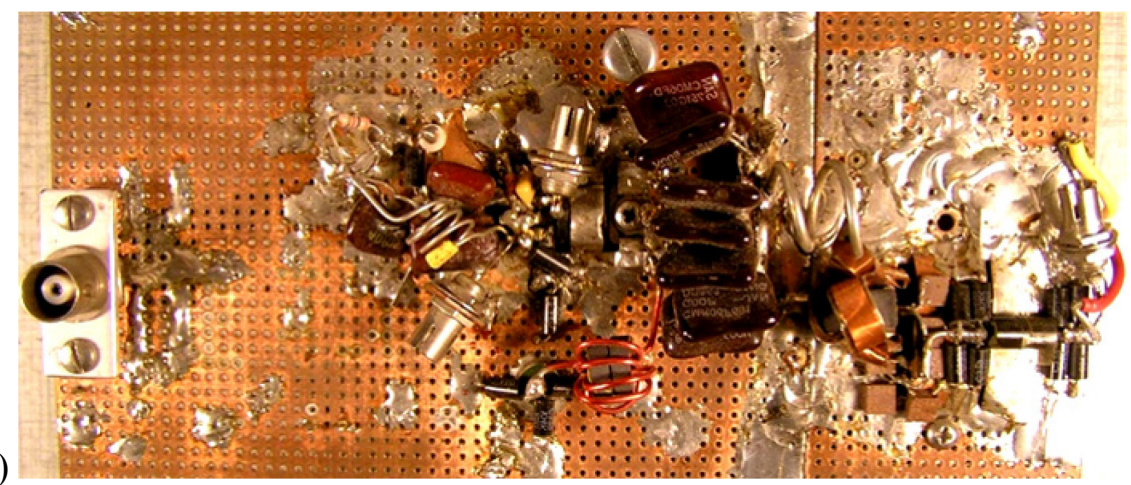

Fig. 1. (a) Schematic of the experimental converter in [4] (driver not included) and (b) photograph of the 100-W 14-MHz converter in [6] (courtesy of Dr. Richard Redl).

Implementations at HF and VHF bands have become common during the last two decades, where solutions based on the class- $\Phi_{2}$ inverter [11] are highlighted for their high-efficiency, low-voltage stress and fast transient response performance. In Fig. 2a and Fig. 2b, the schematic and photograph of the inverter in [11] are presented. The resonant leg formed by $\mathrm{L}_{\mathrm{MR}}-\mathrm{C}_{\mathrm{MR}}$ imposes a low impedance across the switch at the second harmonic. Together with the rest of components, a quasi-trapezoidal drain-tosource voltage waveform may be achieved with the desired low peak value, while also maintaining near ZVS and ZVDS conditions. A complete $110-\mathrm{MHz}$ class- $\Phi_{2}$ boost converter is also included in Fig. 2c [12], with a power stage based on a RF LDMOS device and a Schottky rectifier, complemented by a self-oscillating resonant gate driving circuit. 


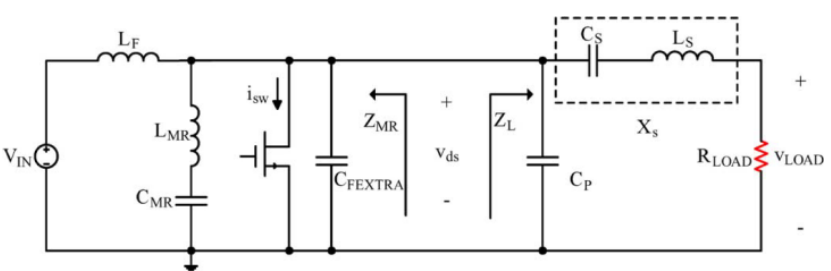

(a)

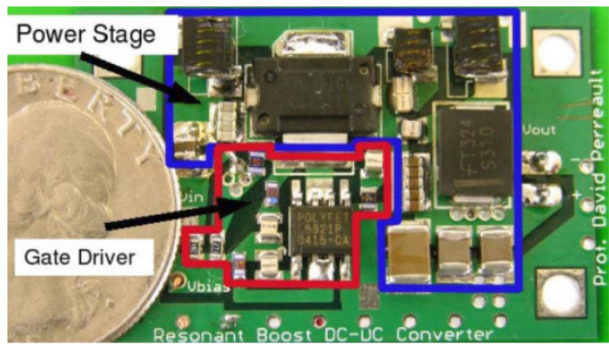

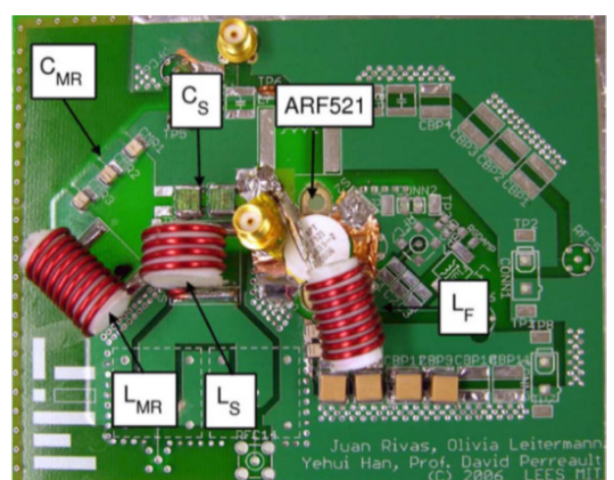

(b)

(c)

Fig. 2. (a) Schematic and (b) photograph of the $30-\mathrm{MHz}$ class- $\Phi_{2}$ inverter in [11], based on the ARF521 MOSFET. (c) Photograph of a complete $110-\mathrm{MHz}$ class- $\Phi_{2}$ boost converter, with the output voltage control circuitry placed on the other side of the PCB [12] (courtesy of Prof. Dave Perreault, MIT).

The approach was scaled to microwave frequencies as early as 1999 [13]. A low-power $64 \%$ efficient $4.5-\mathrm{GHz}$ microstrip planar converter was demonstrated with a $86 \%$ efficient GaAs MESFET class-E PA and a 83\% efficient Schottky diode rectifier, with the layout shown in Fig. 3. When feedback coupling equal to the saturated gain of the PA is provided between output and input, the class-E amplifier is converted to an oscillator with conversion efficiency equal to the PAE, and this oscillator was used in [13] together with the rectifier to provide a dc-to-dc converter with no RF inputs, with a slightly reduced efficiency of $57 \%$ at $725 \mathrm{~mW}$ output power.

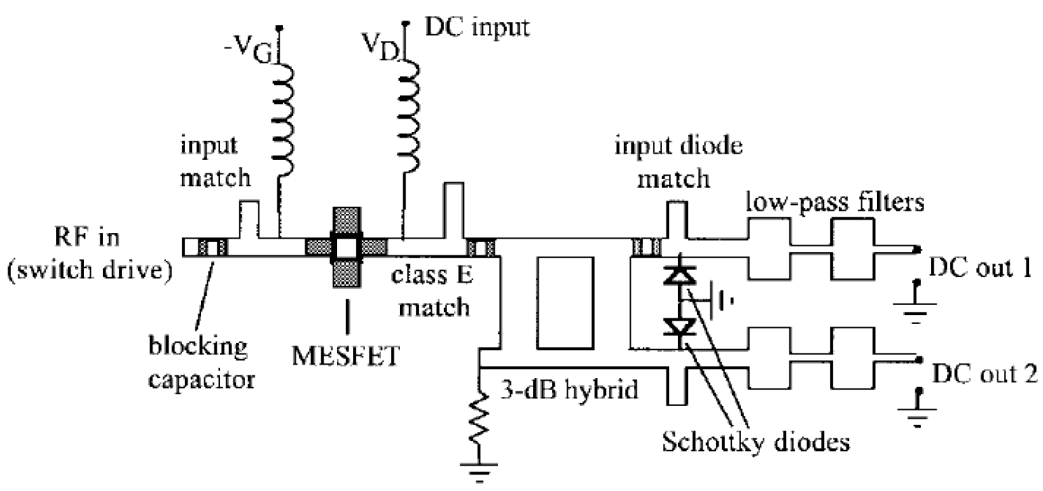

Fig. 3. Layout of a class-E dc-dc converter switching at $4.5 \mathrm{GHz}$ [13]. The converter uses a class-E inverter (PA) with a GaAs MESFET and a balanced microwave Schottky diode rectifier. It achieves $64 \%$ efficiency for a $3-\mathrm{V}$ dc input and a $87 \Omega$ load. 


\section{Class-E ReCTIFIER AND Class-E ${ }^{2}$ DC/DC CONVERTER}

Keeping frequency dependent switching loss under control, the soft switching features of the class-E circuit found use not only in high-frequency dc-to-ac power inversion, but also in rectification. The ac-to-dc conversion is the time-reversal dual of dc-to-ac conversion, according to a principle described first in 1990 by Hamill [14].

\section{A. Time Reversal Duality}

Any resonant amplifier may be transformed into a resonant rectifier of the same operating class according to this principle. The rectifier switch voltage and current waveforms are time-reversed versions of the corresponding switch waveforms in the inverter:

and

$$
\begin{aligned}
& v_{R}(t)=v_{I}(-t) \\
& i_{R}(t)=-i_{I}(-t)
\end{aligned}
$$

leading to a simple relation between their instantaneous powers:

$$
p_{R}(t)=v_{R}(t) \cdot i_{R}(t)=-v_{I}(-t) \cdot i_{I}(-t)=-p_{I}(-t)
$$

Averaged over a cycle, the mean powers in these dual networks have opposite signs, meaning the direction of energy flow is reversed in the rectifier for the desired ac-to-dc conversion.

Based on the above, the class-E inverter circuit in Fig. 4a transforms into the class-E rectifier in Fig. 4b. Analyzed in detail in [15], this is one of the many possible topologies, with rectification of active, or synchronous type, where the gate drive signal of the switching transistor needs to be properly synchronized with the ac excitation. Under $50 \%$ duty cycle operation and with the rest of assumptions from [2], the class-E PA in Fig. 4a is seen by its drain voltage supply as a dc resistance $R_{d c}=1 /\left(\pi \cdot \omega \cdot C_{p}\right)$.

For a DC load of this value at the output of the class-E rectifier, as in Fig. 4b, it presents a resistive input impedance to the ac source equal to the well-known nominal terminating condition, $R_{a c}=0.1836 /\left(\omega \cdot C_{p}\right)$. 
a)
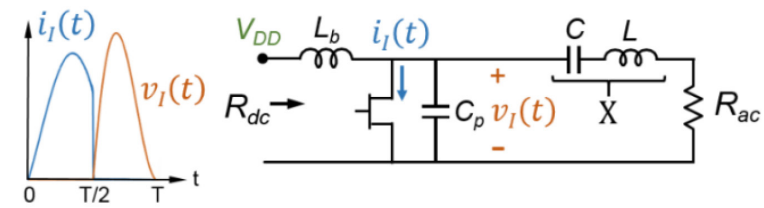

b)

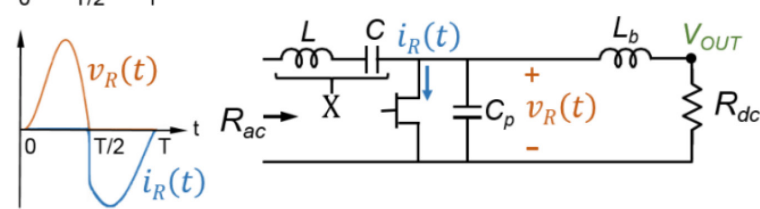

c)

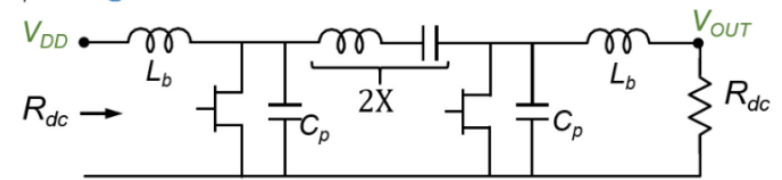

Fig. 4. (a) The class-E inverter or PA, and (b) its transistor-based time-reversed dual, a classE synchronous rectifier. (c) A basic class- $E^{2}$ dc-to-dc converter obtained when cascading (a) and (b). For operation at RF/microwave frequencies, the parallel capacitance $\left(\mathrm{C}_{\mathrm{p}}\right)$ is generally provided by the device output capacitance $\left(\mathrm{C}_{\text {out }}\right)$. Characteristic waveforms for the switch voltage and current are also shown in (a) and (b).

Under appropriate operating conditions, class-E rectifiers may work the same if using diodes or transistors. However, a reduced efficiency may be expected from diode-based topologies at low output voltages, due to the conduction loss in excess determined by the forward voltage drop of a diode. While an active rectifier requires a driver circuit, not only adding complexity but also consuming power, it may offer a unique capability for output voltage regulation [1]. Diode-based rectifier implementations are common at HF and VHF bands, but sufficiently fast Schottky diodes capable of handling high current and voltage levels are rarely available at UHF and higher frequencies, pointing to transistor-based rectifiers as the only choice for high-power RF-to-dc conversion at these bands. The intrinsic drain-to-gate feedback path in the RF FET devices to be employed may also help avoiding the need for the gate driving circuit.

\section{B. Class- $E^{2}$ Resonant Converter}

The class-E rectifier was conceived for the implementation of the double class-E or class- $\mathrm{E}^{2}$ resonant converter in [16]. As depicted in Fig. 4c, when cascading the circuits in Fig. $4 \mathrm{a}$ and $4 \mathrm{~b}$, the rectifier provides the load resistance $R_{a c}$ required by the inverter. Therefore, both circuits may operate under the desired soft-switching conditions without additional circuit elements. For ideal lossless operation, the output de voltage (VOUT) would equal $V_{D D}$. 
This converter was proposed with frequency-based output voltage control [16], following similar approaches to the pioneer works in [3-5]. The thinned-out method [17], the PWM or on/off and phase-based techniques [18] are among other valid strategies for voltage regulation [19]. Up to the low VHF band, class-E $E^{2}$ converter topologies usually incorporate diode-based rectifiers. The need for a gate driving circuit in the inverter side or the minimization of conduction losses in low voltage and high current applications have been addressed in these configurations. Solutions in Fig. 5 have come from the use of an oscillating inverter [20], or of multiphase topologies with interleaved cells [21], respectively.

(a)

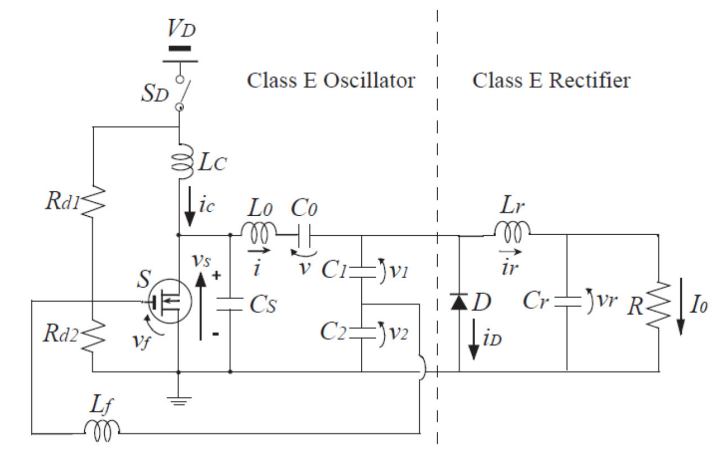

(b)

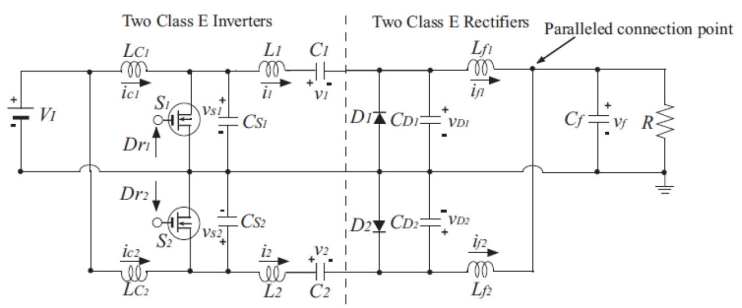

(c)

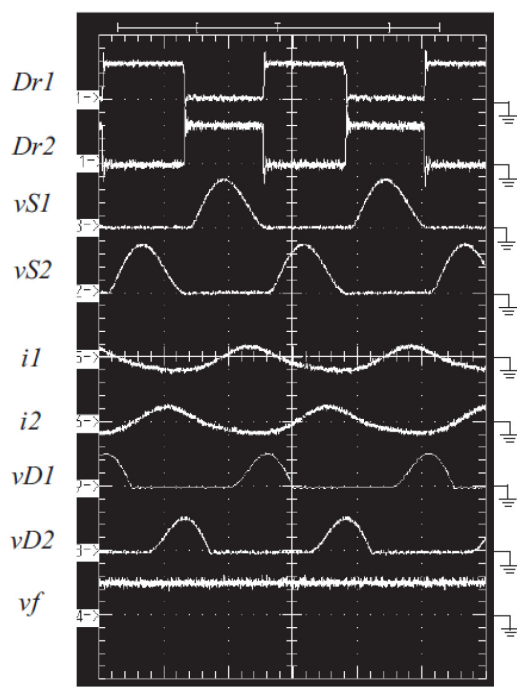

Fig. 5. Circuit topologies of class- $\mathrm{E}^{2}$ converters by Chiba University researchers: (a) $1.55 \mathrm{~W}$ converter with oscillating inverter at $2 \mathrm{MHz}$ from [20], and (b) $3.2 \mathrm{~W}$ interleaved converter operating at $1 \mathrm{MHz}$ from [21]. (c) Experimental waveforms for the converter in Fig. 5b, also from [21].

While the synchronous operation of an active rectifier requires a second ac source to drive the gate of its transistor, self-synchronous operation is an attractive alternative for $\mathrm{RF} /$ microwave implementations. Relying on power coupled from the drain to the gate through the feedback capacitance, $C_{g d}$, and the use of a highly reflective termination at the gate $[22,23]$, the transistor may be turned on without a second source and with the same performance as that obtained for the optimum phase and amplitude of the synchronous drive signal, but with higher overall efficiency if the power of the drive signal is taken into account. 


\section{RECENT APPLiCATIONS AND DESIGN EXAMPLES}

There is increased interest in class-E diode or FET-based rectifiers for efficiently recovering power from an incident RF signal in energy harvesting and far-field wireless power transmission applications (WPT). As an example, a recent synchronous rectifier demonstrated in $0.13 \mu \mathrm{m}$ CMOS technology at $2.4 \mathrm{GHz}$ [24] is intended for wireless sensors that do not require batteries. A photograph of the $850 \mu \mathrm{m}$ × $870 \mu \mathrm{m}$ rectifier die is reproduced in Fig. 6a, and the power efficiency and output voltage profiles versus the available power are plotted in Fig. $6 \mathrm{~b}$ for a load in the optimum conversion range.

(a)

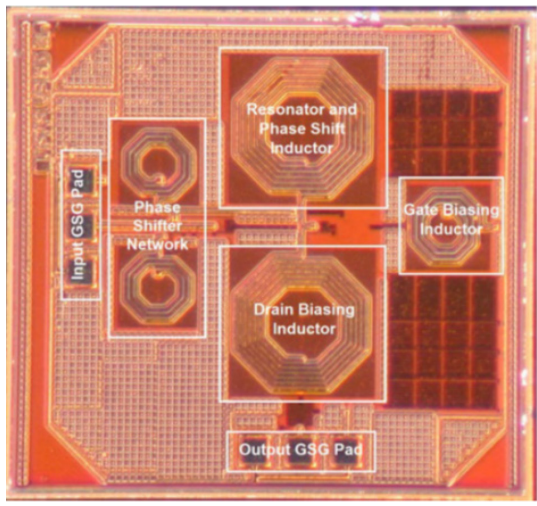

(b)

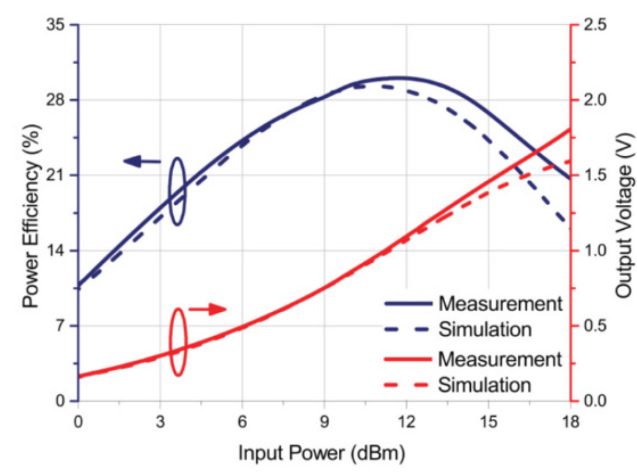

Fig. 6. (a) Class-E synchronous rectifier in [24]. (b) Power efficiency and output voltage as a function of available power at a $250 \Omega$ load (courtesy of Prof. Thomas Johnson, UBC).

Most of the rectifiers reported in the literature are the rectifying stages of the above described double class-E resonant power converter. Class- $\mathrm{E}^{2}$ topologies with a rectifier wirelessly connected to the inverter are also becoming common, at hundreds of $\mathrm{kHz}$ or a few $\mathrm{MHz}$, for implementing inductive or resonant WPT links. While the Wireless Power Consortium (WPC) and the Power Matters Alliance (PMA) WPT standards are based on the inductive coupling method, with a frequency adjustable from 87 to 357 $\mathrm{kHz}$, the Alliance for Wireless Power (A4WP) standard employs the magnetic resonance method, with an operation frequency of $6.78 \mathrm{MHz}$ [25]. In Fig. 7a, an example of tunable class- $\mathrm{E}^{2}$ converter application at $6.78 \mathrm{MHz}$ is presented [26], aimed at maintaining a high efficiency while also ensuring stable output power under variable operating conditions (different coil relative position and dc load). A comparison of the measured efficiency and output power evolution with load resistance for a coupling factor $(k)$ of 0.3 is presented in Fig. $7 \mathrm{~b}$ and Fig. 7c for illustration purposes. 


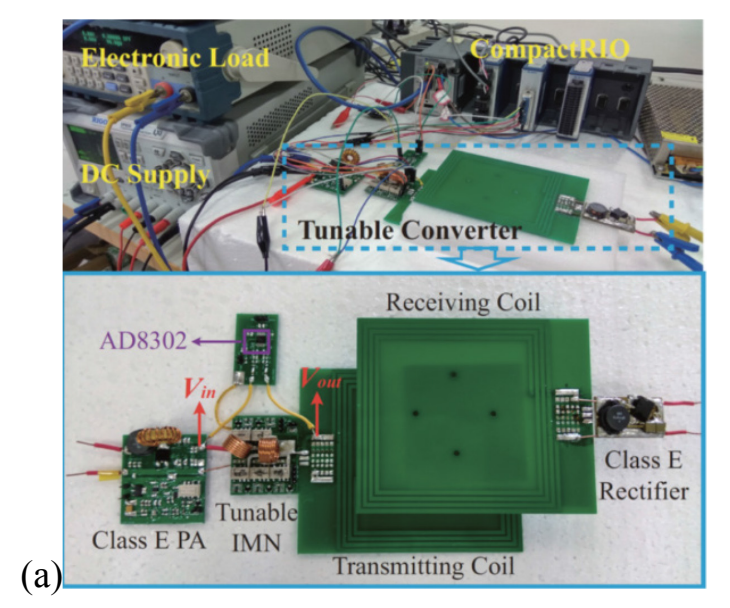

(a) Transmitting Coil

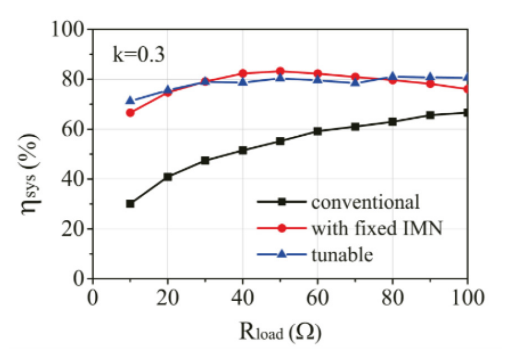

(b)

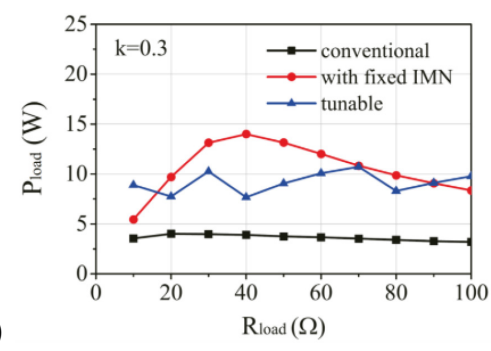

Fig. 7. (a) Dynamically controlled class-E ${ }^{2}$ dc-to-dc converter at $6.78 \mathrm{MHz}$ for WPT [26]. Comparison of (b) efficiency and (c) output power performance versus dc load with $k=0.3$ for a conventional topology, a converter with fixed input matching network and a tunable converter.

\section{A. Class-E Rectifiers}

Two comparative examples of diode- and transistor-based class-E low-power rectifiers, for use in far-field WPT, are described in this section. The class-E rectifier in Fig. 8a from [27] employs an Avago Tech. HSMS-282 Schottky diode. A peak efficiency value of $74 \%$ was measured at $23 \mathrm{dBm}$ (Fig. $8 \mathrm{~b}$ ), with a recovered voltage linearly following the input amplitude. When the incident power is reduced, the variation in the input impedance affects the performance. An interesting solution to this limitation may come from the use of a resistance compression network (RCN) and a plurality of similar rectifiers. Resistance compression networks [28] are a special class of matching network that provide reduced impedance variation at the RF input as compared with the rectifier inputs. A schematic and a photograph of a four-way transmission line RCN are included in Fig. 8c and Fig. 8d, respectively [29]. 
(a)

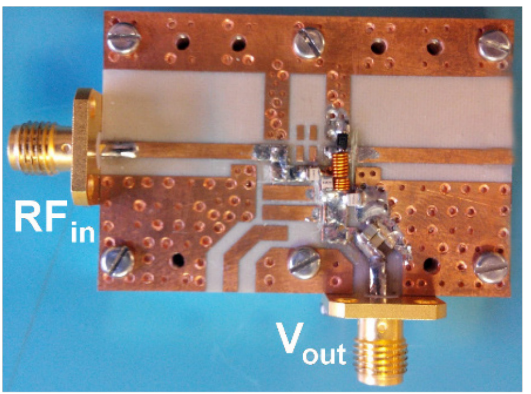

(c)

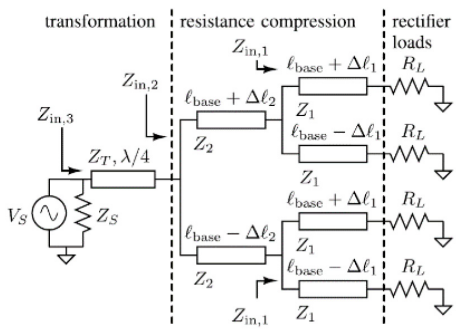

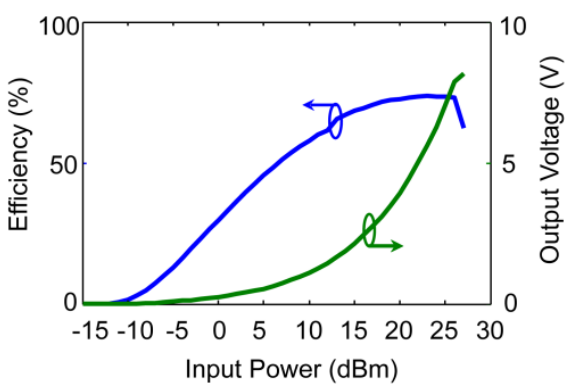

(d)

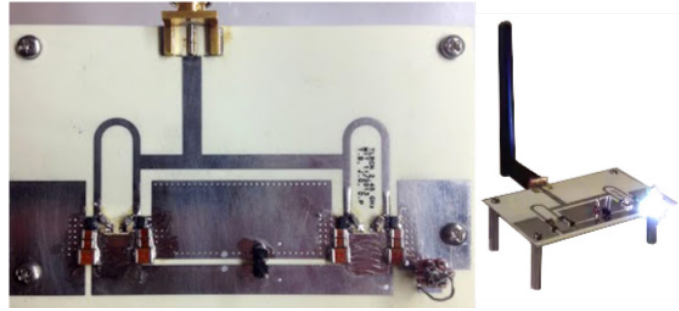

Fig. 8. Diode-based rectifier in [27]: (a) photograph and (b) measured profile. Transmission line RCN in [29]: (c) schematic and (b) photograph (courtesy of Prof. Dave Perreault).

In Fig. 9a, a photograph of a self-synchronous and self-biased rectifier is included, using the VMMK-1218 EpHEMT from Avago Tech. For turning on the device at very low power values, a bootstrap connection of the rectified voltage to the gate terminal is shown in [30]. The gate de voltage can also be forced to follow the input power with an appropriately dimensioned biasing resistor and the small dc current resulting from rectification in the device gate-to-source junction. Measured results for $915 \mathrm{MHz}$ and 2.45 GHz implementations in Fig. 9b show high peak efficiencies $(88 \%$ and $77 \%$, respectively), with a reduction of only 10 points for a power range of $20 \mathrm{~dB}$.

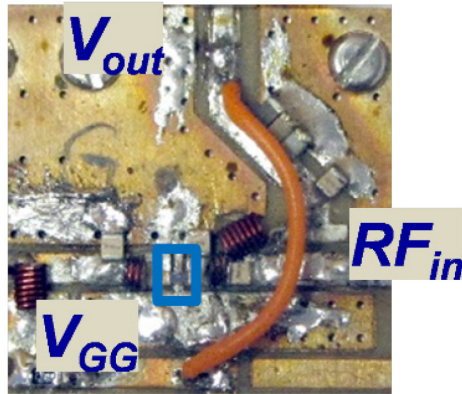

(a)

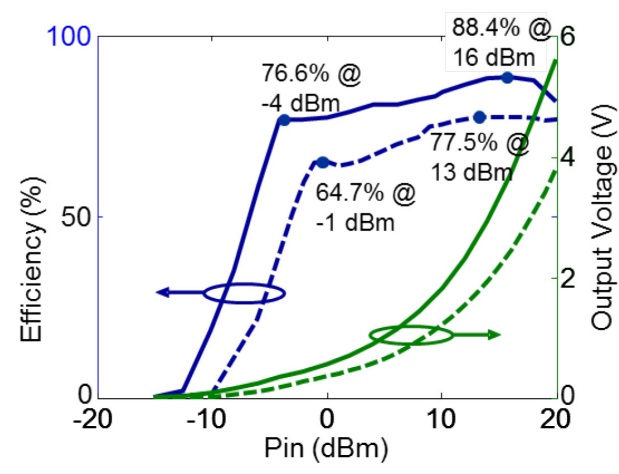

(b)

Fig. 9. E-pHEMT rectifier [30]: (a) photograph and (b) measured results for (-) $900 \mathrm{MHz}$ and (--) $2.45 \mathrm{GHz}$ implementations. 
A promising design methodology for Class-E rectifiers with near resistive input impedance has been recently presented in [31]. Experimentally evaluated with $\mathrm{Si}$ Schottky diodes for VHF rectification, this method should translate well to transistorbased topologies at UHF and the lower microwave bands. In [24], an exhaustive performance comparison of recently reported RF rectifier circuits was included. Integrated and discrete rectifiers, following different topologies and based either on diodes or transistors, were studied. Adding the above examples, class-E circuits have proved to offer competitive efficiency figures for RF power recovery.

\section{B. DC-to-DC Converters}

Examples of UHF/microwave converters shown in this section include synchronous and self-synchronous rectifiers, as well as an oscillating inverter as in [13] and [20]. The photograph and results in Fig. 10 correspond to a synchronous class- $E^{2}$ converter using CGH60030D GaN transistors from Wolfspeed, designed following the technique in [32]. With a peak of nearly $80 \%$, the efficiency is as high as $75 \%$ for $6 \mathrm{~dB}$ of power back-off. Conceived to be employed with FM-control as in [3-5], [16], it can be used as an envelope modulator in a supply-modulated efficient transmitter. Very fast dynamic performance was measured, with a large-signal bandwidth of $56.5 \mathrm{MHz}$ and a slew-rate $2.25 \mathrm{~V} / \mathrm{nS}$ [33], in the state-of-the-art for resonant power converters.

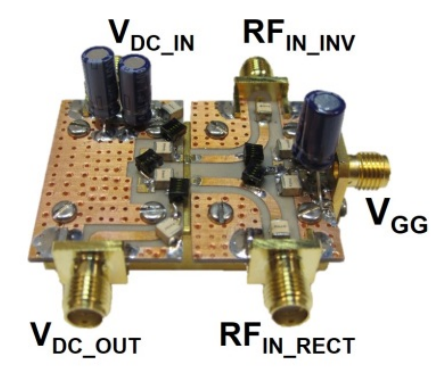

(a)

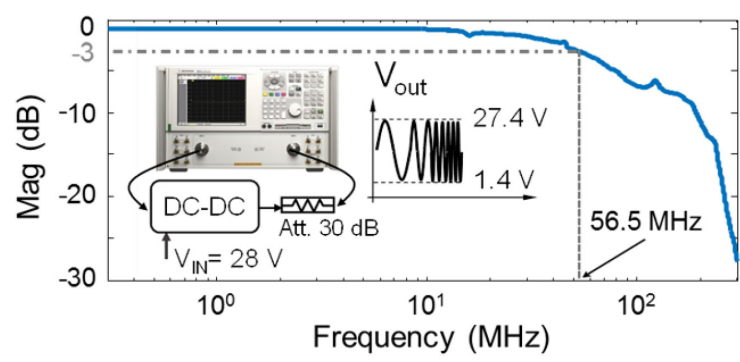

(b)

Fig. 10. Die-based GaN HEMT class-E ${ }^{2}$ converter at $1 \mathrm{GHz}$ : (a) photograph of the implementation together with (b) measured dynamic performance.

In Fig. 11a, a self-synchronous converter requiring only a single RF input, is presented [23]. Implemented with Qorvo 250-nm GaN HEMT devices around 1.2 GHz, with a resonant dc-isolated coupling network between the $\mathrm{PA}$ and rectifier, $75 \%$ total efficiency is demonstrated at $5 \mathrm{~W}$ (Fig. 11b). An oscillating and self-synchronous dc-to- 
dc converter is also successfully demonstrated and tested in [23]. A photograph of this converter is included in Fig. 11c. $80 \%$ total efficiency was measured (Fig. 11d), with a linear frequency-based output voltage control available through the gate-to-source biasing voltage of the inverting device [34].

(a)

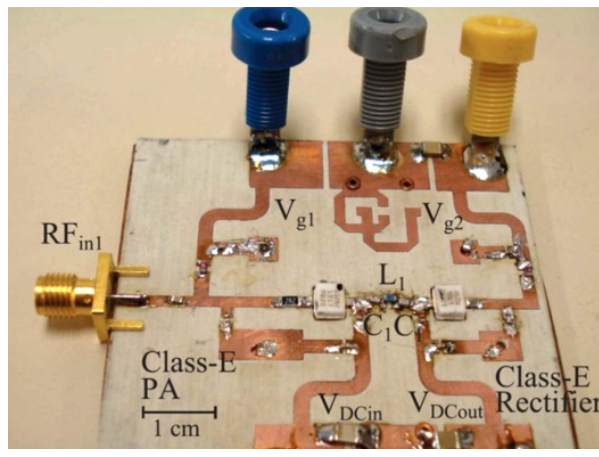

(c)

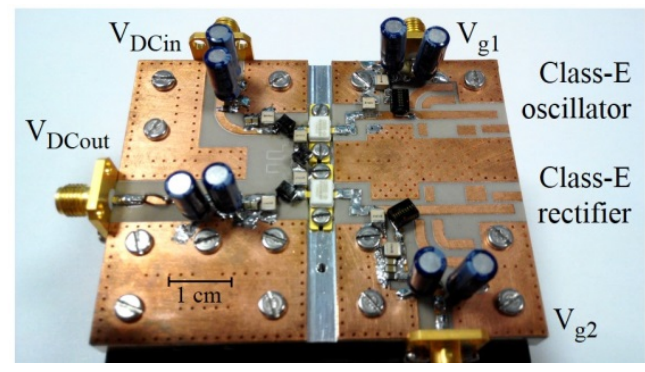

(b)

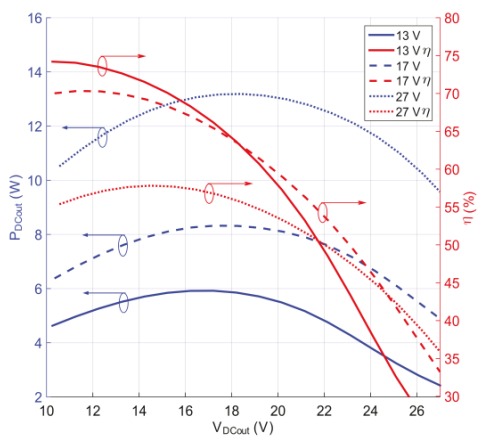

(d)

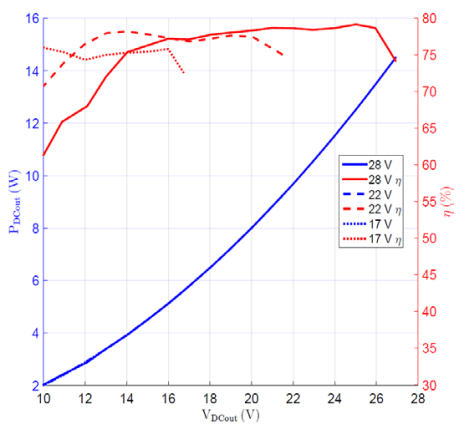

Fig. 11. Class- $\mathrm{E}^{2}$ self-synchronous converter at $1.2 \mathrm{GHz}$ [23]: (a) photograph and (b) measured output power and efficiency profiles with output DC voltage. Class- $\mathrm{E}^{2}$ oscillating and self-synchronous converter at $1 \mathrm{GHz}$ [23]: (c) photograph and (b) measured output power and efficiency profiles with output DC voltage.

The class- $\mathrm{E}^{2}$ architecture was also integrated in the Qorvo 150-nm GaN on SiC process at $4.6 \mathrm{GHz}$ in [35], with a decreased efficiency due to the increased losses expected at this frequency for this particular process. Nevertheless, this $2.3 \mathrm{~mm} \times 3.8 \mathrm{~mm}$ integrated converter is fully monolithic with no external magnetic components, Fig. 12. The total efficiency of around 50\% indicates that both rectifier and amplifier are operating at efficiencies above $70 \%$. 


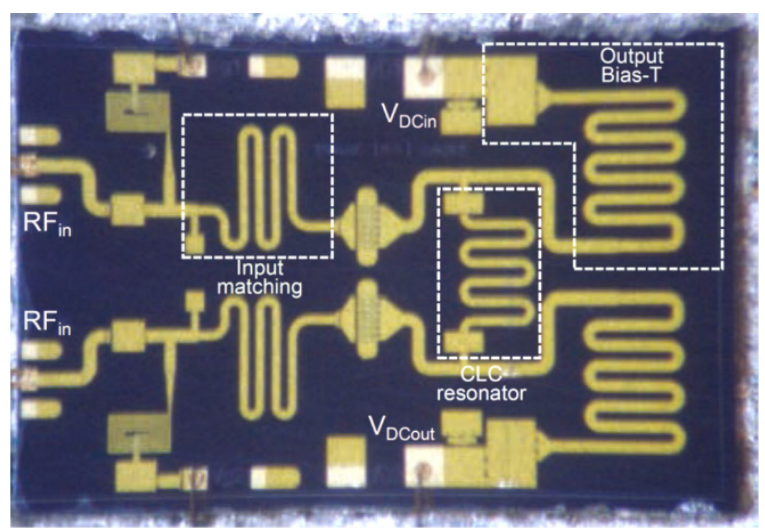

Fig. 12. Fully integrated class- $\mathrm{E}^{2}$ synchronous dc-to-dc converter at $4.6 \mathrm{GHz}$ [35]. The $3.8 \mathrm{~mm} \times 2.3 \mathrm{~mm}$ GaN-on-SiC die using the Qorvo 150-nm gate process demonstrates a total efficiency above $50 \%$ with no external components.

Some of these GaN HEMT based double class-E converters have been integrated with class-E amplifiers [36] for the implementation of polar transmitters. A version with packaged devices from Cree, using PWM or on/off control for the coding of the envelope [19], is presented in Fig. 13a, together with the spectrum resulting from the reproduction of an EDGE signal in Fig. 13b. An average efficiency of $46 \%$ was measured. An alternative implementation with dies, also from Cree, and based on FM coding of the envelope, is presented in Fig. 13c. This architecture integrates a converter based in the one of Fig. 10, later improved in [33]. The RFPA, originally designed as class-E amplifier, may be modified to class-J mode for the operation in a hybrid envelope tracking (ET) - envelope elimination and restoration mode (EER). An auxiliary GaN HEMT was added to reduce the sensitivity of the class- $\mathrm{E}^{2}$ converter to load variations. The spectrum of the reproduced 1c-WCDMA signal has been included in Fig. 13d. An average efficiency of 57\% was measured in this case.
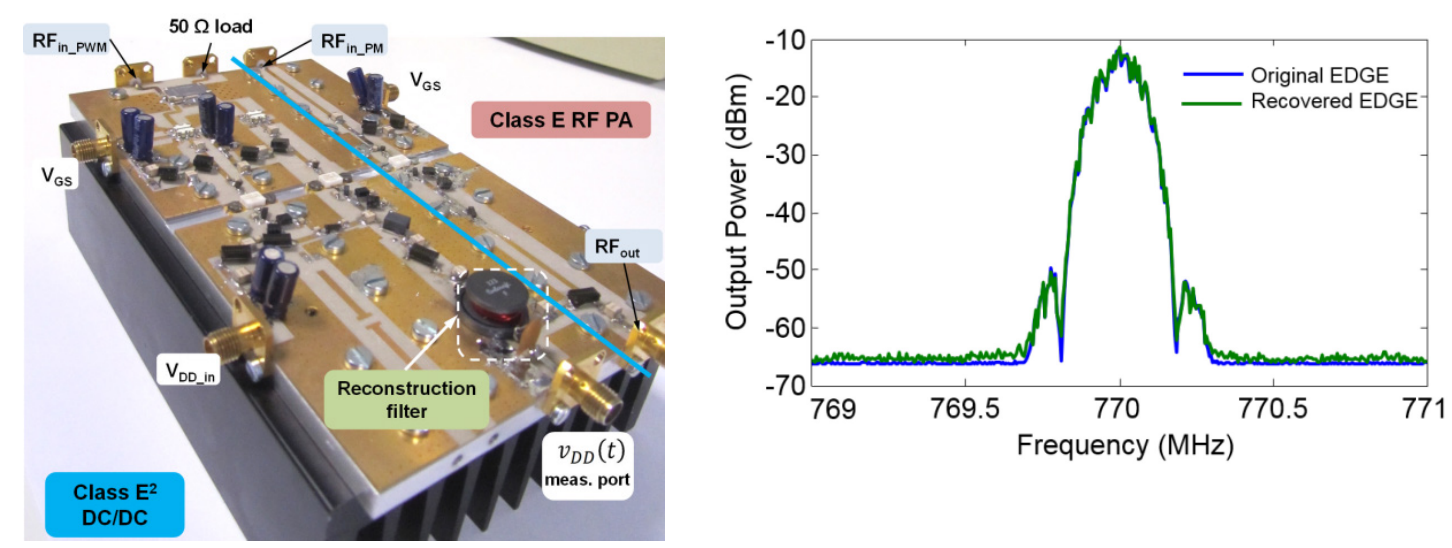

(a)

(b) 
(c)
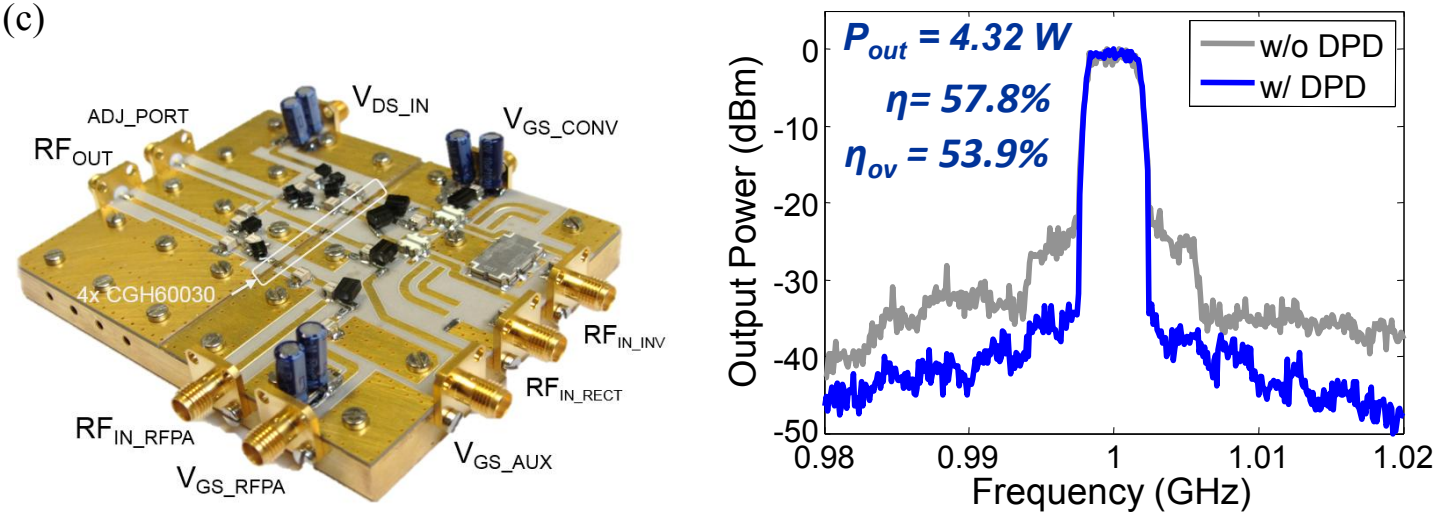

(d)

Fig. 13. Polar transmitter implementations integrating class- $E^{2}$ resonant converters: (a) Packaged device version at $770 \mathrm{MHz}$ from [19] together with the (b) reproduced EDGE signal spectrum. (c) Die based architecture at $1 \mathrm{GHz}$, reproducing a 1c-WCDMA signal in d).

\section{CONCLUSIONS}

The inherent low-loss operation of the class-E topology, introduced worldwide to the $\mathrm{RF} /$ microwave community by Nathan O. Sokal, has found significant applications not only in amplifiers, but also for RF-to-dc and dc-to-dc power conversion [33]. Efficiency values reported for low-power transistor-based class-E rectifiers, designed for RF energy recovery at $915 \mathrm{MHz}$ and $2.45 \mathrm{MHz}$ IMS bands, are close to $90 \%$ and $80 \%$, respectively. Interestingly, the synchronous and self-synchronous class-E operation and time-reversal duality of amplifiers and rectifiers extends to all amplifier classes. Highpower and efficient rectifiers operating in classes $\mathrm{E}, \mathrm{C}, \mathrm{F}, \mathrm{F}^{-1}$ are demonstrated in the UHF and microwave bands using GaN HEMT hybrid technology [22, 37]. Single-ended single-stage, power combined and two-stage GaN MMIC implementations at $\mathrm{X}$ band have also been demonstrated with efficiencies up to $70 \%[38,39]$ at several watts of output power in harmonically-terminated PAs operated as rectifiers, as discussed theoretically in [22].

The integration of inverters (PAs) and rectifiers in double class-E power converters is discussed through several hybrid UHF and MMIC microwave experimental examples. Applications include high efficiency inductive or resonant near-field wireless power transmission links, and fast response dc-to-dc converters. The operation of converters at higher switching frequencies is mainly motivated by the interest in miniaturization and improved control bandwidth. The frequency dependence of gating, switching and magnetic losses imposes significant constraints on this direction [40]. Resonant gate driving and soft switching stand as fundamental techniques to minimize these device 
loss mechanisms, reason why the RF design concepts behind the ZVS and ZVDS classE power amplifier have been so attractive for power electronic specialists. Switching fast enough may also help minimizing or even eliminating magnetic materials [40], enabling not only PCB but also MMIC integration of the power converter [35].

In table I, a performance comparison of recently reported RF dc-to-dc converters is included. All of them are research oriented implementations, authors are not aware of any actual uses of the class-E power converter in products. Although far from being competitive in terms of conversion efficiency with well stablished $\mathrm{kHz}$ topologies, highfrequency class-E based or derived power converters may provide efficiency values close to $90 \%$ at $110 \mathrm{MHz}$ [12], $80 \%$ at $980 \mathrm{MHz}$ [23] and $65 \%$ at $4.5 \mathrm{GHz}$ [13]. The power density may be far from the expected in research oriented hybrid implementations as [23], but its miniaturization up to the MMIC level has been shown to be feasible [35]. Wide bandwidth values and slew rates have been reported, in the state-of-the-art for switching converters. The limitation in the measured efficiency at UHF and microwave bands may be partially associated to the fact that the employed RF transistors have not been fabricated for this purpose, but for their use in class-AB current source power amplifiers. The estimated losses for the $980 \mathrm{MHz}$ converter in [23] showed that the biggest contributor to the dissipated power was the transistor's ONstate resistance. Significant advances in high breakdown technologies, the optimization of the device layout for soft switching operation and the selection of the most appropriate architecture and control method [40], may all lead to further improvements. 
Table I. Performance Comparison of Recently Reported RF Power Converters

\begin{tabular}{|c|c|c|c|c|c|c|c|}
\hline Ref. & Freq. (MHz) & $P_{\text {out }}(\mathrm{W})$ & $\eta_{\text {ov }}(\%)$ & Technology & Type & BW $3 \mathrm{~dB}(\mathrm{MHz})$ & Size $(\mathrm{mm} \times \mathrm{mm})$ \\
\hline [21] & 1 & 3.2 & 90 & MOSFET & $\begin{array}{l}\text { Interleaved } \\
\text { class-E }{ }^{2}\end{array}$ & $\mathrm{~N} / \mathrm{R}$ & $\mathrm{N} / \mathrm{R}$ \\
\hline$[20]$ & 2 & 1.55 & 78.9 & MOSFET & $\begin{array}{l}\text { Class-E }{ }^{2} \text { (with } \\
\text { oscillating } \\
\text { inverter) }\end{array}$ & $\mathrm{N} / \mathrm{R}$ & $\mathrm{N} / \mathrm{R}$ \\
\hline [41] & 20 & 16 & 92.5 & $\mathrm{GaN}$ & $\begin{array}{l}\text { Synchronous } \\
\text { buck } \\
\text { converter }\end{array}$ & $\mathrm{N} / \mathrm{R}$ & $2 \times 2$ \\
\hline [42] & 25 & 68 & 96.5 & $\mathrm{GaN}$ & $\begin{array}{l}4 \text { phase } \\
\text { synchronous } \\
\text { buck convert }\end{array}$ & 20 & $\mathrm{~N} / \mathrm{R}$ \\
\hline [43] & 30 & 220 & 87.5 & MOSFET & Class $\Phi_{2}$ & $\mathrm{~N} / \mathrm{R}$ & $\mathrm{N} / \mathrm{R}$ \\
\hline [44] & 100 & 7 & 91 & $\mathrm{GaN}$ & $\begin{array}{l}\text { Synchronous } \\
\text { buck converter }\end{array}$ & 20 & $4 \times 4$ \\
\hline [12] & 110 & 25 & 87 & LDMOS & $\begin{array}{l}\text { Class } \Phi_{2} \\
\text { resonant boost } \\
\text { conv. }\end{array}$ & 1 & $27 \times 49 *$ \\
\hline [45] & 233 & 0.55 & 82 & CMOS & $\begin{array}{l}\text { Integrated buck } \\
\text { dc- }- \text { dc } \\
\text { converter }\end{array}$ & $\mathrm{N} / \mathrm{R}$ & $3.5 \times 4.5$ \\
\hline [41] & 400 & 5 & $67 \%$ & $\mathrm{GaN}$ & $\begin{array}{l}\text { Synchronous } \\
\text { buck } \\
\text { converter }\end{array}$ & $\mathrm{N} / \mathrm{R}$ & $2 \times 2$ \\
\hline [19] & 780 & 11.5 & 72 & $\mathrm{GaN}$ & Class- $E^{2}$ & 11 & $144 \times 88$ \\
\hline$[23]$ & 980 & 12.9 & 79.4 & $\mathrm{GaN}$ & $\begin{array}{l}\text { Class- }^{2} \\
\text { (no RF inputs } \\
\text { required) }\end{array}$ & 32 & $60 \times 77$ \\
\hline [33] & 1090 & 8.5 & 76.7 & $\mathrm{GaN}$ & $\begin{array}{l}\text { Class-E }{ }^{2} \\
\text { (with self- } \\
\text { synchronous } \\
\text { rectifier) }\end{array}$ & 56.5 & $44 \times 35$ \\
\hline [13] & 1200 & 0.053 & 64 & $\begin{array}{l}\mathrm{GaN} \\
\mathrm{GaAs}\end{array}$ & 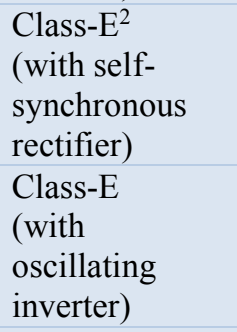 & $\mathrm{N} / \mathrm{R}$ & $\begin{array}{l}56 \times 60 \\
140 \times 70\end{array}$ \\
\hline$[35]$ & 4600 & 0.6 & 48 & GaN MMIC & Class-E $E^{2}$ & $\mathrm{~N} / \mathrm{R}$ & $3.8 \times 2.5$ \\
\hline
\end{tabular}

\section{ACKNOWLEDGMENTS}

The authors would like to acknowledge support in part by the Spanish Ministry of Economy, Industry and Competitiveness (MINECO) through TEC2014-58341-C4-1-R and TEC2017-83343-C4-1-R projects, co-funded with FEDER, and in part by Lockheed Martin Endowed Chair at the University of Colorado. They also want to thank the kind contributions to the IEEE MTT-S Int. Microwave Symp. paper [33] or to this extended 
manuscript by Dr. Frederick Raab, Dr. Ronald J. Gutmann, Dr. Richard Redl, Prof. David J. Perreault and Prof. Thomas Johnson.

\section{REFERENCES}

[1] M. K. Kazimierczuk and D. Czarrkowski, Resonant Power Converters, NJ: John Wiley \& Sons, 2011.

[2] N. O. Sokal and A. D. Sokal, "Class E, a new class of high-efficiency tuned single-ended switching power amplifiers," IEEE Journal Solid-State Circuits, vol. SC-10, pp. 168-176, June 1975.

[3] R. J. Gutmann, "Application of RF circuit design principles to distributed power converters," IEEE Trans. Industrial Electron. Control Instrum., vol. IECI-27, pp. 156-164, Aug. 1980.

[4] R. Redl, B. Molnár, and N. O. Sokal, "Class E resonant regulated de/dc power converters: analysis of operations, and experimental results at $1.5 \mathrm{MHz}$," IEEE Trans. Power Electron., vol. PE-1, pp. 111-120, April 1986.

[5] R. Redl, B. Molnár, and N. O. Sokal, "Small-signal dynamic analysis of regulated class E dc/dc converters," IEEE Trans. Power Electron., vol. PE-1, pp. 121-128, April 1986.

[6] R. Redl and N. O. Sokal, "A 14-MHz 100-Watt class E resonant converter: principles, design considerations and measured performance," Proc. Power Electronics Show and Conference, San Jose, CA, Oct. 1986, vol. 1, pp. 68-77.

[7] B. Molnar, "Basic limitations on waveforms achievable in single-ended switchingmode tuned (Class E) power amplifiers," IEEE Journal Solid-State Circuits, vol. 19, no. 1, pp. 144-146, Feb 1984.

[8] R. Redl and N. Sokal, "A new Class-E DC/DC converter family with reduced parts count: Derivation, topologies, and design considerations," Proc. Tech. Papers 4th Int. High Freq. Power Convers. Conf., Naples, FL, pp. 395-415, May 1989.

[9] K. Ikeda and S. Mori, "Class-E power amplifier using second harmonic resonance," Joint Technical Conf. on Circuit/Systems, Computers and Communications, pp. 451-456, Nov. 1988. 
[10] M. Acar, A. J. Annema, and B. Nauta, "Analytical design equations for class-E power amplifiers," IEEE Trans. Circuits Systems - I: Reg. Papers, vol. 54, no. 12, pp. 2706-2717, Dec. 2007.

[11] J. M. Rivas, Y. Han, O. Leitermann, A. D. Sagneri, and D. J. Perreault, "A highfrequency resonant inverter topology with low-voltage stress," IEEE Trans. Power Electron., vol. 23, no. 4, pp. 1759-1771, July 2008.

[12] R. C. N. Pilawa-Podgurski, A. D. Sagneri, J. M. Rivas, D. I. Anderson and D. J. Perreault, "Very-High-Frequency resonant boost converters," IEEE Trans. Power Electron., vol. 24, no. 6, pp. 1654-1665, June 2009.

[13] S. Djukic, D. Maksimovic and Z. Popovic, "A planar 4.5-GHz dc-dc power converter," IEEE Trans. Microwave Theory Tech., vol. 47, pp. 1457-1460, Aug. 1999.

[14] D. C. Hamill, "Time reversal duality and the synthesis of a double class E dc-dc converter," 21st Power Electron. Specialist Conf., PESC'90, pp. 512-521, 1990.

[15] M. K. Kazimierczuk, "Analysis of class E zero-voltage-switching rectifier," IEEE Trans. Circuits Systems, vol. 37, pp. 747-755, 6, June 1990.

[16] M. K. Kazimierczuk, J. Jozwik, "Resonant dc/dc converter with class-E inverter and class-E rectifier," IEEE Trans. Industrial Electron., vol. 36, pp. 468-478, Nov. 1989.

[17] M. Fujii, T. Suetugu, H. Koizumi, K. Shinoda and S. Mori, "Resonant dc/dc converter with class E inverter and class E synchronous rectifier using thinned-out method," IEEE Int. Symp. Circuits Systems, Seattle, WA, 1995, pp. 1119-1122.

[18] C. Q. Hu, X. Z. Zhang, and S. P. Huang, "Class-E combined-converter by phaseshift control," IEEE Power Electronics Specialists Conf., Milwaukee, WI, 1989, pp. 229-234.

[19] J. A. García, R. Marante and M. N. Ruiz, "GaN HEMT class E2 resonant topologies for UHF dc/dc power conversion," IEEE Trans. Microwave Theory Tech., vol. 60, pp. 4220-4229, Dec. 2012.

[20] H. Hase, H. Sekiya, Jianming Lu and T. Yahagi, "Resonant dc/dc converter with class E oscillator," IEEE Int. Symp. Circuits Systems, pp. 720-723, 2005.

[21] M. Katayama, H. Sekiya and T. Yahagi, "An interleaved class $E^{2}$ dc/dc converter," IEEE Int. Symp. Circuits Systems, pp. 2833-2836, 2008. 
[22] M. Roberg, T. Reveyrand, I. Ramos, E. A. Falkenstein and Z. Popovic, "High efficiency harmonically terminated diode and transistor rectifiers," IEEE Trans. Microwave Theory Tech., vol. 60, pp. 4043-4052, Dec. 2012.

[23] I. Ramos, M. N. Ruiz, J. A. García, D. Maksimovic and Z. Popovic, "GaN microwave dc-dc converters," IEEE Trans. Microwave Theory Tech., vol. 63, pp. 4473-4482, Dec. 2015.

[24] S. Dehghani and Thomas Johnson, "A $2.4 \mathrm{GHz}$ CMOS class-E synchronous rectifier," IEEE Trans. Microwave Theory Tech., vol. 64, pp. 1655-1666, May 2016.

[25] Y. J. Park et al., "A Triple-Mode Wireless Power-Receiving Unit With $85.5 \%$ System Efficiency for A4WP, WPC, and PMA Applications," IEEE Trans. Power Electronics, vol. 33, no. 4, pp. 3141-3156, April 2018.

[26] S. Liu, M. Liu, S. Han, X. Zhu and C. Ma, "Tunable Class E² DC-DC Converter with High Efficiency and Stable Output Power for $6.78 \mathrm{MHz}$ Wireless Power Transfer," IEEE Trans. Power Electron., vol. PP, no. 99, pp. 1-1.

[27] L. Rizo, D. Vegas, M. N. Ruiz, R. Marante, L. Cabria and J. A. García, "Class-E amplifier and rectifier for a wireless link with secure signal and simultaneous power transmission," 2016 IEEE Wireless Power Transfer Conference (WPTC), pp. 1-3, Aveiro, 2016.

[28] Y. Han, O. Leitermann, D. A. Jackson, J. M. Rivas and D. J. Perreault, "Resistance Compression Networks for Radio-Frequency Power Conversion," IEEE Trans. Power Electronics, vol. 22, no. 1, pp. 41-53, Jan. 2007.

[29] T. W. Barton, J. M. Gordonson and D. J. Perreault, "Transmission line resistance compression networks and applications to wireless power transfer," IEEE Journal Emerging Selected Topics Power Elect., vol. 3, pp. 252-260, March 2015.

[30] M. N. Ruiz and J. A. García, "An E-pHEMT self-biased and self-synchronous class E rectifier," IEEE MTT-S Int. Microwave Symp., pp. 1-4, 2014.

[31] J. A. Santiago-González, K. M. Elbaggari, K. K. Afridi and D. J. Perreault, "Design of class $\mathrm{E}$ resonant rectifiers and diode evaluation for VHF power conversion," IEEE Trans. Power Electron., vol. 30, pp. 4960-4972, Sept. 2015.

[32] J. A. García, R. Marante, M. N. Ruiz and G. Hernández, “A 1 GHz frequencycontrolled class $\mathrm{E}^{2} \mathrm{dc} / \mathrm{dc}$ converter for efficiently handling wideband signal envelopes," IEEE MTT-S Int. Microwave Symp., pp. 1-4, 2013. 
[33] J. A. García and Z. Popović, "Class-E rectifiers and power converters," EEE MTTS Int. Microwave Symp., Honololu, HI, 2017, pp. 1327-1330.

[34] J. A. García, M. N. Ruiz, D. Vegas, M. Pampín, and A. Mediavilla, "UHF power conversion with GaN HEMT class-E ${ }^{2}$ topologies," IEEE Compound Semiconductor Integrated Circuit Symp. (CSICS), Miami, FL, 2017, pp. 1-4.

[35] I. Ramos and Z. Popovic, "A microwave monolithically integrated distributed 4.6 GHz dc-dc converter", IEEE MTT-S Int. Microwave Symp., pp.1-4, 2016.

[36] Z. Popović and J. A. García, "Microwave class-E power amplifiers," IEEE MTT-S Int. Microwave Symp., Honololu, HI, 2017, pp. 1323-1326.

[37] M. Litchfield, S. Schafer, T. Reveyrand and Z. Popović, "High-efficiency X-band MMIC GaN power amplifiers operating as rectifiers," IEEE MTT-S Int. Microwave Symp., pp. 1-4, 2014.

[38] M. Coffey, S. Schafer and Z. Popović, "Two-stage high-efficiency X-Band GaN MMIC PA/ rectifier," IEEE MTT-S Int. Microwave Symp., pp. 1-4, 2015.

[39] Z. Popovic, I. Ramos, T. Reveyrand and M. Litchfield, "Microwave transistor power rectifiers and applications," IEEE Compound Semiconductor Integrated Circuit Symp. (CSICS), Austin, TX, 2016, pp. 1-4.

[40] D. J. Perreault, "In search of powerful circuits: developments in very high frequency power conversion," Princeton, April 28, 2014, http://acee.princeton.edu/wp-content/uploads/2014/06/David-Perreault-SlidePresentation.pdf.

[41] A. Sepahvand, Y. Zhang and D. Maksimovic, "High efficiency 20-400 MHz PWM converters using air-core inductors and monolithic power stages in a normally-off GaN process," IEEE Applied Power Electronics Conference and Exposition (APEC), pp. 580-586, Long Beach, CA, 2016.

[42] Y. Zhang, J. Strydom, M. de Rooij and D. Maksimović, "Envelope tracking GaN power supply for 4G cell phone base stations," IEEE Applied Power Electronics Conference and Exposition (APEC), pp. 2292-2297, Long Beach, CA, 2016.

[43] J. M. Rivas et al., "A very high frequency DC-DC converter based on a class resonant inverter," IEEE Power Electron. Specialists Conf., pp. 1657-1666, 2008.

[44] Y. Zhang, M. Rodriguez, and D. Maksimovic, "100 MHz, 20 V, 90\% efficient synchronous buck converter with integrated gate driver," IEEE Energy Conv. Congr. and Expo, pp. 3664-3671, Sep. 2014. 
[45] P. Hazucha et al., "A 233-MHz 80\%-87\% efficient four-phase DC-DC converter utilizing air-core inductors on package," IEEE J. Solid-State Circuits, vol. 40, no. 4, pp. 838-845, Apr. 2005. 